Old Dominion University

ODU Digital Commons

$3-2018$

Solutions for Fermi Questions, March 2018:

Question 1: Air Pressure on Waves; Question 2:

Weight of Toner

Larry Weinstein

Follow this and additional works at: https://digitalcommons.odu.edu/physics_fac_pubs

Part of the Fluid Dynamics Commons, and the Science and Mathematics Education Commons 


\section{Solutions for Fermi Questions, March 2018: Question 1: Air pressure on waves;}

Question 2: Weight of toner

Larry Weinstein

Citation: The Physics Teacher 56, A167 (2018); doi: 10.1119/1.5025278

View online: https://doi.org/10.1119/1.5025278

View Table of Contents: http://aapt.scitation.org/toc/pte/56/3

Published by the American Association of Physics Teachers

\section{Articles you may be interested in}

Solution to the January, 2018 Challenge Touched by an angle

The Physics Teacher 56, A181 (2018); 10.1119/1.5025279

ELECTROMAGNETIC WAVES

The Physics Teacher 56, 133 (2018); 10.1119/1.5025284

Answer to March 2018 Figuring Physics

The Physics Teacher 56, A133 (2018); 10.1119/1.5025277

The march of the electrons

The Physics Teacher 56, 181 (2018); 10.1119/1.5025302

A Person Stands on a Balance in an Elevator: What Happens When the Elevator Starts to Fall?

The Physics Teacher 56, 156 (2018); 10.1119/1.5025292

A Tale of Two Slinkies: Learning about Model Building in a Student-Driven Classroom

The Physics Teacher 56, 134 (2018); 10.1119/1.5025285

\section{Make the Switch: Modular Circuits

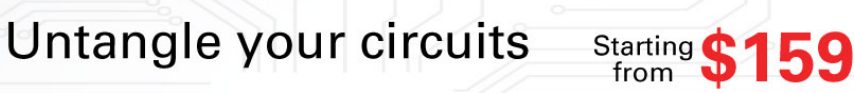
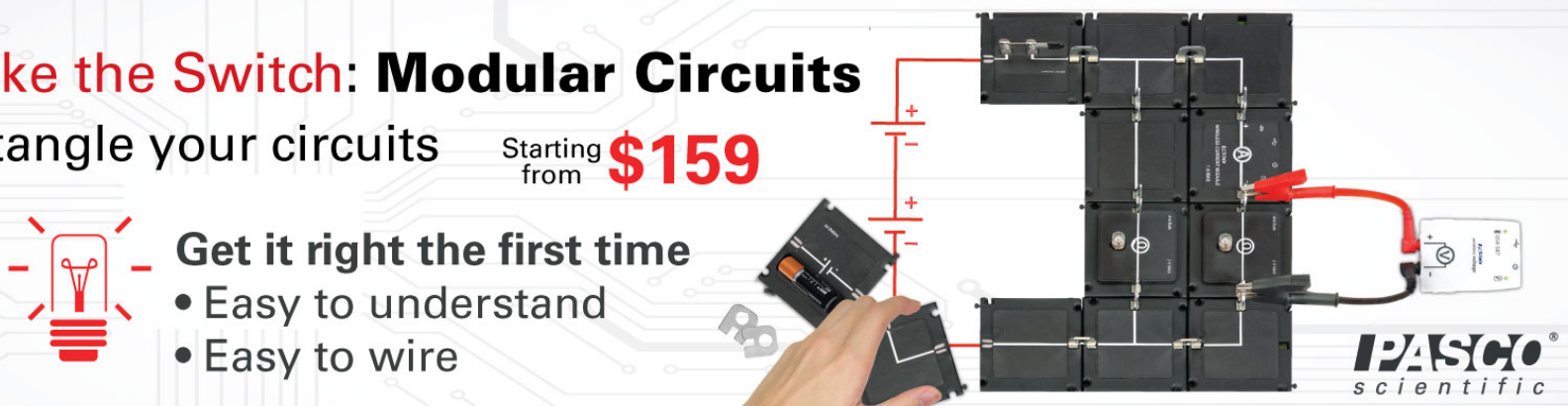


\section{Fermi Questions}

\section{Solutions for Fermi Questions, March 2018}

\section{Duestion 1: Air pressure on waves}

When the wind is blowing, what is the difference between the air pressure at the crest and at the trough of an ocean wave due to the Bernoulli effect?

Answer: Wind blowing over the water creates waves. The longer the distance over which the wind blows (the greater the "fetch"), the bigger the waves. There are two effects: the wind blows on the wave crests, exerting a force parallel to the wind direction due to air resistance, and there is a pressure differential between the wave crests, which experience the full wind speed, and the wave troughs, which do not.

If the wave is high enough, then the wave trough will experience a wind speed of zero. In that case, the pressure differential due to the Bernoulli effect will be

$$
\Delta P=\frac{1}{2} \rho v^{2}
$$

so we need to estimate the density and speed of the air. The density of air can be estimated in one of two ways. If we remember that air has a mass of about $30 \mathrm{~g} /$ mole (more than molecular nitrogen and less than molecular oxygen) and that a mole of gas at STP has a volume of $22 \mathrm{~L}$, then we can calculate that air has a density of $1.4 \mathrm{~g} / \mathrm{L}$ or

$1.4 \mathrm{~kg} / \mathrm{m}^{3}$. Alternatively, we can estimate that the density of air is about $10^{3}$ times less than the density of water, or about $1 \mathrm{~kg} / \mathrm{m}^{3}$.

The wind blows hard over the ocean, at more than $10 \mathrm{mph}$ and less than $100 \mathrm{mph}$, giving an estimate of $30 \mathrm{mph}$ or $15 \mathrm{~m} / \mathrm{s}$. We can now calculate the pressure differential as

$$
\begin{aligned}
\Delta P & =\frac{1}{2} \rho v^{2} \\
& =(0.5)\left(1 \mathrm{~kg} / \mathrm{m}^{3}\right)(15 \mathrm{~m} / \mathrm{s})^{2} \\
& =10^{2} \mathrm{~Pa} .
\end{aligned}
$$

The important unit to use here is not $\mathrm{Pa}$, but the equivalent height of the water column. One atmosphere is $10^{5} \mathrm{~Pa}$ and corresponds to a $30-\mathrm{m}$ tall water column. The wind-driven pressure difference of $10^{2} \mathrm{~Pa}$ is $10^{3}$ times smaller and therefore corresponds to a 30-mm ( $\sim$ in) water column. Thus the Bernoulli effect is unlikely to have a significant influence on the formation of water waves.

Copyright 2018, Lawrence Weinstein.

\section{Duestion 2: Weight of toner}

How much heavier is a 100 -page printed document than 100 blank pages? (Thanks to Emily Kandel of Scarsdale, NY, for suggesting the question.)

Answer: At about $\$ 1$ per gram, printer toner is already one of the most expensive substances on Earth (see Guesstimation 2.0 for details), so let's hope that there's not too much on each page. We can estimate the mass of toner on the page in several different ways. We can use the mass of toner in a cartridge and estimate the number of copies it can print; or we can estimate the area and thickness of toner on a page. Let's try both methods and see how they compare.

First, let's estimate the mass of one piece of paper. A ream of $8.5 \times 11$ paper is about 2 in thick, so it has a volume

$$
\begin{aligned}
V & =l w h \\
& =(5 \mathrm{~cm})(20 \mathrm{~cm})(30 \mathrm{~cm})=3 \times 10^{3} \mathrm{~cm}^{3} .
\end{aligned}
$$

At $1 \mathrm{~g} / \mathrm{cm}^{3}$, this will have a mass of $3 \times 10^{3} \mathrm{~g}$. Therefore, one sheet of paper will have a mass of $6 \mathrm{~g}$. Since 100 printed text pages do not feel much heavier than 100 unprinted pages, the toner cannot have a mass more than about $10 \%$ of the paper, or $600 \mathrm{mg} / \mathrm{sheet}$.

Black toner for laser printers costs about $\$ 50$ (more than $\$ 20$ and less than $\$ 100$ ) and can print about 3000 sheets of text (more than $10^{3}$ and less than $10^{4}$ ). We can estimate the mass of toner two ways. There is more than $10 \mathrm{~g}$ and less than $10^{3} \mathrm{~g}$ of toner in a typical desktopprinter toner cartridge, giving an estimate of $100 \mathrm{~g}$. Alternatively, at $\$ 1$ per gram, the $\$ 50$ toner cartridge contains $50 \mathrm{~g}$ of toner. Going with the higher estimate, $100 \mathrm{~g}$ of toner spread over $3 \times 10^{3}$ sheets of paper gives a toner mass of $30 \mathrm{mg}$ per sheet.

Next we can estimate the area and thickness of toner on the page. In order to be opaque, the thickness must be more than the wavelength of light, $5 \times 10^{-7} \mathrm{~m}$, and it must be less than the $10^{-4} \mathrm{~m}$ that I can feel with my finger tips. This gives a thickness estimate of $10^{-5} \mathrm{~m}$. We can estimate the area covered in toner either globally or by estimating the area of one letter and the number of letters per page. Let's make life easy (for once) by doing a global estimate. A page must have less than $10 \%$ and more than $10^{-3}$ of its area covered in toner, giving an estimate of $10^{-2}$ or $6 \mathrm{~cm}^{2}$. The volume of toner is then 


$$
\begin{aligned}
V_{\text {toner }} & =A t \\
& =\left(6 \mathrm{~cm}^{2}\right)\left(10^{-3} \mathrm{~cm}\right) \\
& =6 \times 10^{-3} \mathrm{~cm}^{3} .
\end{aligned}
$$

Assuming a toner density of 1 (in $\mathrm{g} / \mathrm{cm}^{3}, \mathrm{~kg} / \mathrm{L}$ or tons/ $\mathrm{m}^{3}$ ), this yields a toner mass of $6 \mathrm{mg}$ per sheet, which is five times less than the previous estimate.

Note that if the entire page is heavily covered in toner, as is often the case with color images, then the mass of toner on the page is about 100 times greater, or $600 \mathrm{mg}$ per sheet.

Copyright 2018, Lawrence Weinstein. 